rule to his class ; holding one in his hand, he expounded in detail the steps necessary to perform a multiplication. "We take as a simple example three times four," he said, and after appropriate explanations he continued, "Now we arrive at the result ; three times four is II $8 . "$ The class smiled. "That is near enough for our purpose," said Reynolds. It may. be imagined that the average student was often puzzled; but nevertheless, the number of scientific engineers of high standing that he trained is a testimony to his teaching power, when he had the right material with which to deal. That power was not one of imparting knowledge but rather of stimulating thought.

Not long ago a representative of the University of Manchester lectured in the. United States. At the conclusion of the lecture a gentleman stepped out from the audience, and addressing the lecturer, said: "I understand that you come from Manchester. I owe all my success in life to Osborne Reynolds, and I ask you to accept a cheque for the benefit of the University as a sign of gratitude." No one could wish for a higher testimonial than that.

\title{
The Fossil Anthropoid Ape from Taungs.
}

By Sir ARTHur KeITH, F.R.S.

THE discovery of fossil remains of a "man ape" in South Africa raises many points of great interest for those who are studying the evolution of man and of man-like apes. No doubt when Prof. Dart publishes his full monograph of his discovery, he will settle many points which are now left open, but from the facts he has given us, and particularly from the accurate drawing of the endocranial cast and skull in profile, it is even now possible for an onlooker to assess the importance of his discovery. I found it easy to enlarge the profile drawing just mentioned to natural size and to compare it with corresponding drawings of the skulls of children and of young apes. When this is done, the peculiarities of Australopithecus become very manifest.

Prof. Dart regrets he has not access to literature which gives the data for gauging the age of young anthropoids. In the specimen he has discovered and described, the first permanent molar teeth are coming into use. Data which I collected 25 years ago show that these teeth reach this stage near the end of the 4th year, two years earlier than is the rule in man and two years later than is the rule in the higher monkeys. In evolution towards a human form there is a tendency to prolong the periods of growth. Man and the gorilla have approximately the same size of brain at birth; the rapid growth of man's brain continues to the end of the 4 th year; in the gorilla rapid growth ceases soon after birth.

Prof. Dart recognises the many points of similarity which link Australopithecus to the great anthropoid apes-particularly to the chimpanzee and gorilla. Those who are familiar with the facial characters of the immature gorilla and of the chimpanzee will recognise a blend of the two in the face of Australopithecus, and yet in certain points it differs from both, particularly in the small size of its jaws.

In size of brain this new form is not human but anthropoid. In the 4 th year a child has reached $8 \mathrm{I}$ per cent. of the total size of its brain; at the same period a young gorilla has obtained 85 per cent. of its full size, a chimpanzee 87 per cent. From Prof. Dart's accurate diagrams one estimates the brain length to have been II $8 \mathrm{~mm}$. - a dimension common in the brains of adult and also juvenile gorillas. The height of the brain above the ear-holes also corresponds in both Australopithecus and the gorilla-about $70 \mathrm{~mm}$. But in width, as Prof. Dart has noted, the gorilla greatly exceeds the new anthropoid; in the gorilla the width of brain is usually about $100 \mathrm{~mm}$. ; in Australopithecus the width is estimated at $84 \mathrm{~mm}$. The average volume of the interior of gorillas' skulls (males and females) is 470 c.c., but occasional individuals run up to 620 c.c. One may safely infer that the volume of the brain in the juvenile Australopithecus described by Prof. Dart must be less than 450 c.c., and if we allow a $I_{5}$ per cent. increase for the remaining stages of growth, the size of the adult brain will not exceed 520 c.c. At the utmost the volume of brain in this new anthropoid falls short of the gorilla maximum. Even if it be admitted, however, that Australopithecus is an anthropoid ape, it is a very remarkable one. It is a true long-headed or dolichocephalic anthropoid - the first so far known. In all living anthropoids the width of the brain is 82 per cent. or more of its length; they are round-brained or brachycephalic; but in Australopithecus the width is only $7 \mathrm{I}$ per cent. of the length. Here, then, we find amongst anthropoid apes, as among human races, a tendency to roundness of brain in some and to length in others. On this remarkable quality of Australopithecus Prof. Dart has laid due emphasis.

This side-to-side compression of the head taken in conjunction with the small size of jaws throw a side light on the essential features of Australopithecus. The jaws are considerably smaller than those of a chimpanzee of a corresponding age, and much smaller than those of a young gorilla. There is a tendency to preserve infantile characters, a tendency which has had much to do with the shaping of man from an anthropoid stage. The relatively high vault of the skull of Australopithecus and its narrow base may also be interpreted as infantile characters. It is not clearly enough recognised that the anthropoid and human skulls undergo remarkable growth changes leading to a great widening of the base and a lowering or flattening of the roof of the skull. In Australopithecus there is a tendency to preserve the fœtal form.

When Prof. Dart produces his evidence in full he may convert those who, like myself, doubt the advisability of creating a new family for the reception of this new form. It may be that Australopithecus does turn out to be "intermediate between living anthropoids and man," but on the evidence now produced one is inclined to place Australopithecus in the same group or sub-family as the chimpanzee and gorilla. It is an allied genus. It seems to be near akin to both, differing from them in shape of head and brain and in a tendency to the retention of infantile characters. The geological evidence will help to settle its relation-

NO. 2885 , vOL. I I 5$]$ 
ships. One must suppose we are dealing with fossil remains which have become embedded in the stalagmite of a filled-up cave or fissure of the limestone cliff.

May I, in conclusion, thank Prof. Dart for his full and clear description, and particularly for his accurate drawings. One wishes that discoverers of such precious relics would follow his example, and, in place of reproducing crude tracings and photographs, give the same kind of drawings as an engineer or an architect prepares when describing a new engine or a new building.

\section{By Prof. G. Elliot Smith, F.R.S.}

IT is a great tribute to Prof. Dart's energy and insight to have discovered the only fossilised anthropoid ape so far obtained from Africa, excepting only the jaw of the diminutive Oligocene Propliopithecus from the Egyptian Fayum. Whether or not the interpretation of the wider significance he has claimed for the fossil should be corroborated in the light of further information and investigation, the fact remains that his discovery is of peculiar interest and importance.

The simian infant discovered by him is an unmistakable anthropoid ape that seems to be much on the same grade of development as the gorilla and the chimpanzee without being identical with either. So far Prof. Dart does not seem to have "developed" the specimen far enough to expose the crowns of the teeth and so obtain the kind of evidence which in the past has provided most of our information for the identification of the extinct anthropoids. Until this has been done and critical comparisons have been made with the remains of Dryopithecus and Sivapithecus, the two extinct anthropoids that approach nearest to the line of man's ancestry, it would be rash to push the claim in support of the South African anthropoid's nearer kinship with man. Prof. Dart is probably justified in creating a new species and even a new genus for his interesting fossil : for if such wide divergences between the newly discovered anthropoid and the living African anthropoids are recognisable in an infant, probably not more than four years of age, the differences in the adults would surely be of a magnitude to warrant the institution of a generic distinction.

Many of the features cited by Prof. Dart as evidence of human affinities, especially the features of the jaw and teeth mentioned by him, are not unknown in the young of the giant anthropoids and even in the adult gibbon.

The most interesting, and perhaps significant, distinctive features are presented by the natural endocranial cast. They may possibly justify the claim that Australopithecus has really advanced a stage further in the direction of the human status than any other ape. But until Prof. Dart provides us with fuller information and full-size photographs revealing the details of the object, one is not justified in drawing any final conclusions as to the significance of the evidence.

The size of the brain affords very definite evidence that the fossil is an anthropoid on much the same plane as the gorilla and the chimpanzee. But while its brain is not so large as the big gorilla-cast used for comparison by Prof. Dart, it is obvious that it is bigger than a chimpanzee's brain and probably well above the average for the gorilla. But the fossil is an imperfectly developed child, whose brain would probably have increased in volume to the extent of a fifth had it attained the adult status. Hence it is probable the brain would have exceeded in bulk the biggest recorded cranial capacity for an anthropoid ape, about $65^{\circ}$ c.c. As the most ancient and primitive human brain case, that of Pithecanthropus, is at least 900 c.c. in capacity, one might regard even a small advance on 650 c.c. as a definite approach to the human status. The most suggestive feature (in Prof. Dart's Fig. 5, p. I97) is the position of the sulcus lunatus and the extent of the parietal expansion that has pushed asunder the lunate and parallel sulci-a very characteristic human feature.

When fuller information regarding the brain is forthcoming-and no one is more competent than Prof. Dart to observe the evidence and interpret it-I for one shall be quite prepared to admit that an ape has been found the brain of which points the way to the emergence of the distinctive brain and mind of mankind. Africa will then have purveyed one more surprise-but only a real surprise to those who do not know their Charles Darwin. But what above all we want Prof. Dart to tell us is the geological evidence of age, the exact conditions under which the fossil was found, and the exact form of the teeth.

\section{By Sir Arthur Smith Woodward, F.R.S.}

THE new fossil from Taungs is of special interest as being the first-discovered skull of an extinct anthropoid ape, and Prof. Dart is to be congratulated on his lucid and suggestive preliminary description of the specimen. As usual, however, there are serious defects in the material for discussion, and before the published first impressions can be confirmed, more examples of the same skull are needed.

First, as Prof. Dart remarks, the fossil belongs to an immature individual with the milk-dentition, and, so far as can be judged from the photograph, I see nothing in the orbits, nasal bones, and canine teeth definitely nearer to the human condition than the corresponding parts of the skull of a modern young chimpanzee. The face seems to be relatively short, but the lower jaw of the Miocene Dryopithecus has already shown that this must have been one of the characters of the ancestral apes. The symphysis of the lower jaw may owe its shape and the absence of the "simian shelf" merely to immaturity; but it may be noted that a nearly similar symphysis has been described in an adult Dryopithecus, of which it may also be said that " the anterior symphyseal surface is scarcely less vertical than that of Heidelberg man " (see diagrams in Quart. Journ. Geol. Soc., vol. 70, I9I4, pp. 31 7, 3I9).

Secondly, the Taungs skull lacks the bones of the brain-case, so that the amount and direction of distortion of the specimen cannot be determined. I should therefore hesitate to attach much importance to rounding or flattening of any part of the brain-cast, and would even doubt whether the relative dimensions of the cast of the cerebellum can be relied on. Confirmatory evidence is needed of the reality of appearances in such a fossil.

In the absence of knowledge of the skulls of the fossil anthropoid apes represented by teeth and fragmentary jaws in the Tertiary formations of India, it is premature to express any opinion as to whether the direct

$$
\text { NO. } 2885 \text {, VOL. I I } 5 \text { ] }
$$


ancestors of man are to be sought in Asia or in Africa. The new fossil from South Africa certainly has little bearing on the question.

Palæontologists will await with interest Prof. Dart's detailed account of the new anthropoid, but cannot fail to regret that he has chosen for it so barbarous (LatinGreek) a name as Australopithecus.

\section{By Dr. W. L. H. Duckworth.}

PROF. DART'S description of the fossil skull found at Taungs in Bechuanaland shows that this specimen possesses exceptional interest and importance. Should the claims made on its behalf prove good, then its discovery will in effect be comparable to those of the Pithecanthropus remains, of the Mauer mandible and the Piltdown fragments. In the following paragraphs I venture to make some comments based upon perusal of the article published in NATURE of February 7 .

First of all, the fact that the fragments came immediately under notice of so competent an anatomist as Prof. Dart establishes confidence in the thoroughness of the scrutiny to which they have been subjected. That the history of the specimen should be known precisely from the time of its release from the limestone matrix, provides another cause for satisfaction.

The specimen itself at once raises a number of questions, and, as Prof. Dart evidently realises, these fall into at least two categories. The first question arising out of the discovery is the status of the individual represented by these remains. But the answer to that question, and the presence of such a creature in South Africa, affect other problems. The latter include inquiry into the probable locality of origin of the simian and human types, and the search for evidence of dispersion from a centre, or along a line of successive migrations.

In dealing with the first problem, Prof. Dart has surveyed a considerable number of structural details, and he concludes that the specimen represents an extinct race of apes intermediate between living anthropoid apes and mankind. The specimen comprises the greater part of a skull with the lower jaw still in place (or nearly so). The number and characters of the teeth testify to the immaturity of the individual. The evidence on the last-mentioned point is quite definite, and interest thus comes to be centred in the status assigned to the specimen; namely, that of a form intermediate between the living anthropoid apes and man himself.

Prof. Dart places the specimen on the side of the living anthropoid apes in relation to the interval separating these from man. At the same time, it is claimed that this new form of ape is more man-like than any of the existing varieties of anthropoid apes ; and so it comes about that the decision turns on the claims made for the superiority of the new ape to these other forms.

The report shows that (as noted above) many structural details have been scrutinised, and that all accessible parts of the specimen have been examined. The observations relate not only to the external parts of the skull and lower jaw, but also to the endocranial parts exposed to view by the partial shattering of the brain-case. The claims advanced on behalf of the higher status of the specimen are based, therefore, upon a number and variety of such details. Should Prof.
Dart succeed in justifying these claims, the status he proposes for the new ape-form should be conceded. Much will depend on the interpretation of the features exhibited by the surface of the brain, as also upon that of all the characters connected therewith; and since Prof. Dart is so well equipped for that aspect of the inquiry, his conclusions must needs carry special weight there. In regard to the brain and its characters, I find the tracing of the contour of an endocranial cast in a gorilla-skull shown in Fig. 6 rather surprisingly flattened, and almost suggestive of the influence of age.

Among the anatomical characters enumerated in the article, some appear to me to possess a higher value in evidence than others. As good points in favour of the claims, there may be cited, in addition to the cerebral features to which reference has just been made, the level of the lower border of the nasal bones in relation to the lower orbital margins, the (small) length of the nasal bones, the lack of brow-ridges (even though the first permanent tooth has appeared fully), the steeplyrising forehead, and the relatively short canine teeth.

On the other hand, I feel fairly certain that some of the other characters mentioned are related preponderantly to the youthfulness of the specimen. Fully to appreciate the latter, demands not only the handling of it, but also thorough survey of a collection of immature (anthropoid ape) crania. The development of the "shelf" at the back of the symphysis of the lower jaw may almost certainly be delayed in some individuals (gorillas). Even the level of the lower border of the nasal bones is subject to some variation, and in young gorillas before the first permanent tooth has emerged fully, that level may be (as in man) above the level of the orbital margin. Generally, the elimination and detachment of features influenced largely by the factor of age demand special attention.

If, however, the good points can be justified, then these characters of youth will not gravely affect the final decision.

However these discussions may end, the record remains of the occurrence of an anthropoid ape some two thousand miles to the south of the nearest region providing a record of their presence. So far as the illustrations allow one to judge, the new form resembles the gorilla rather than the chimpanzee, that is, an African, not an Asiatic form of anthropoid ape. In this respect the new ape does not introduce an obviously disturbing factor. Disturbance, and the recasting of disturbed views, might nevertheless be caused in two other directions. Thus, the determination of the geological antiquity of the embedding of the fossil remains might have such an effect, were the estimate such as to carry that event very far back in time. Again, a comparison of the new ape with the fossil forms from India (Siwaliks) remains to be made, and it may be productive of results bearing on the relation of the African and the Asiatic groups. In any case, opinion must needs conform to the situation created by this discovery.

If in these notes there have been passed over those observations and reflections wherewith Prof. Dart has illustrated and supported his views, such omissions are not due to want of appreciation, but to lack of capacity and space for their adequate treatment.

$$
\text { NO. } 2885 \text {, VOL. I I } 5]
$$

